Original Research Paper

\title{
Nonlinear Control of Variable wind Speed Conversion System Based on a Squirrel Cage Induction Generator (SCIG)
}

\author{
Abouobaida Hassan \\ Department of Electrical Engineering, Ecole Mohammadia D'ingénieurs, Mohammed V University, Rabat, Morocco
}

Article history

Received: 24-10-2014

Revised: 20-12-2014

Accepted: 02-01-2015

\begin{abstract}
This study presents a control strategy for a Squirrel Cage Induction Generator (SCIG)-based wind energy conversion system. Control strategies of the $\mathrm{AC} / \mathrm{DC} / \mathrm{AC}$ converter is presented along with the mathematical modeling of the employed configuration. The maximum power point extraction of the wind turbine is addressed along with the proposed strategy. The backstepping approach is introduced to control the generator speed and regulate the flux. The wind system is then simulated in MATLAB-SIMULINK and the developed model is used to illustrate the behavior of the system. The simulation results are presented and discussed at the end of this study.
\end{abstract}

Keyword: Squirrel Cage Induction Generator (SCIG), Grid Power, Unity Power Factor, Wind Energy Conversion System, Maximum Power Point Extraction

\section{Introduction}

The growing need for electrical energy and the will to preserve the nature justifies the use of renewable energy sources. The use of renewable sources for electric power generation has been a huge increase since the past decade. Increased economical and ecological woes have driven researchers to discover newer and better means of generating electrical energy. In this race, the production of electricity by wind turbine is actually the best method in comparison with the energy produced by the solar source conversion and this is due to the price per a kilo watt that is less elevated with respect to the second (Suebkinorn and Neammanee, 2011). Among the most used and available technologies for wind turbines, the Doubly Fed Induction Generator (DFIG) is the most accepted because it presents greater benefits for a reduced conversion structure and efficient energy capture due to variable speed operation.

Different types of electric generators are used for the generation of electric energy from wind. These include the Squirrel Cage Induction Generators (SCIG), the Doubly Fed Induction Generator (DFIG) and the Synchronous Generator (SG) (Suebkinorn and Neammanee, 2011).

The Squirrel Cage Induction Generator (SCIG) is suitable for alternative energy source applications because it is cheap, has simple construction, good power/weight ratio, low maintenance levels and it is robust and easily replaceable. For these reasons, the
SCIG is being strongly considered as a good option in conjunction with the variable speed wind turbines (Trapp et al., 2012).

Variable-speed wind turbines are advantageous for their potential capability of extracting more energy from wind resources. Thus, an MPPT control strategy is necessary to adjust the turbine rotor speed according to the variation of wind speeds so that the tip speed ratio can be maintained at its optimal value.

Several MPPT control algorithms have been proposed in the technical literature. The search control such as Perturb and Observe (P\&O), anemometer-based method and the fuzzy-logic based algorithms are easily implemented and are independent of wind turbine characteristics. In the P\&O algorithm, the turbine speed is varied in small steps and the corresponding change in power is observed. Step changes are effected in a direction so as to move toward MPP. This process is continued until MPP is reached. By using this algorithm, maximum power corresponding to any wind velocity can be captured. But the time taken to reach MPP is long and a considerable amount of power loss takes place during the tracking phase. The anemometer-based MPPT algorithm, the wind velocity is measured and a reference speed for the induction generator corresponding to the Maximum Power Point (MPP) of the present wind velocity is set. Although this is a fast MPPT scheme, the overall cost of the system increases because anemometer is expensive. Fuzzy-control-based scheme is good, but is 
complex to implement. Neural networks could be an alternative approach for the MPPT control, but the requirement for offline training in order to learn the turbine characteristics might be a considerable drawback for several installations. An optimal torque controller that follows a quadratic relation between turbine torque and speed can provide faster dynamic response, however, it needs a priori knowledge of the turbine characteristics (Mesemanolis and Mademlis, 2013).

In the grid-connected system, however, any amount of power generated by the wind energy based (SCIG) can be injected into the grid. Hence, at any wind velocity, the system can be operated at MPP to maximize the generation and utilization of power. The block diagram of a typical grid-connected wind energy conversion system is shown in Fig. 1. The transfer of the power produced by this system is made by two cascaded converters. The first is linked to the network operates as a rectifier and the second operates as an inverter is connected to the grid (Manaullah et al., 2012).

In this study, the problem of controlling $\mathrm{AC} / \mathrm{DC}$ converter is approached using the backstepping technique. While feedback linearization methods require precise models and often cancel some useful nonlinearity, backstepping designs offer a choice of design tools for accommodation of uncertain nonlinearities and can avoid wasteful cancellations.

The backstepping approach is applied to a specific class of switched power converters, namely ac-to-dc converters. In the case where the converter model is fully known the backstepping nonlinear controller is shown to achieve the control objectives i.e., speed and flux control of (SCIG) with respect to wind change. The desired speed is designed online using a an estimate of the speed reference corresponding to operation at maximum power generator wind power. The proposed strategy ensures that the MPP is determined, the generator speed is controlled to its reference value and the close loop system will be asymptotically stable. The stability of the control algorithm is analysed by Lyapunov approach.

This study is structured as follows. Section II presents the modeling of the SCIG system. The detailed control strategy is discussed in section III. Section IV presents and discusses simulation and results followed by conclusions in section $\mathrm{V}$.

\section{Wind Energy Conversion System Modeling}

The wind turbine modeling is inspired from (Manaullah et al., 2012). In the following, the wind turbine components models are briefly described.

\section{The Turbine Model}

The aerodynamic power $P$ captured by the wind turbine is given by Equation 1:

$$
P=\frac{1}{2} \pi \rho R^{2} C p(\lambda) v^{3}
$$

where, the tip speed ratio $\lambda$ is given by Equation 2 :

$\lambda=\frac{R \omega}{v}$

And $v$ is the wind, $\rho$ is the air density, $R$ is the rotor radius and $C p$ is the power coefficient. $\lambda$ is the ratio of turbine blades tip speed to wind speed and $\beta$ is the turbine blades rotational speed. The Generator power as a function of generator speed for different velocity is illustrated in Fig. 2.

The rotor power (aerodynamic power) is also defined by Equation 3:

$P=T_{m} . \omega$

where, $T_{m}$ is the aerodynamic torque and $\omega$ is the wind turbine rotor speed.

The following simplified model is adopted for the turbine Equation 4:

$J \frac{d \omega}{d t}=T_{m}-T_{e m}-K . \omega$

Where:

$T_{e m}=$ The generator electromagnetic torque

$J \quad=$ The turbine total inertia

$K=$ The turbine total external damping

\section{The SCIG Model}

The control system is usually defined in the synchronous $d-q$ frame fixed to either the stator voltage or the stator flux. For the proposed control strategy, the generator dynamic model written in a synchronously rotating frame $d-q$.

The voltages of the windings of the stator and the rotor according to the $d-q$ axes are given by the following relations (Kedjar and Al-Haddad, 2012):

$\left\{\begin{array}{c}v_{s d}=R_{s} i_{s d}+\frac{d \Phi_{s d}}{d t}-\omega_{s} \cdot i_{s q} \\ v_{s q}=R_{s} i_{s q}+\frac{d \Phi_{s q}}{d t}+\omega_{s} i_{s d} \\ v_{r d}=0=R_{r} i_{r d}+\frac{d \Phi_{r d}}{d t}-\omega_{r} \cdot i_{r q} \\ v_{r q}=0=R_{r} i_{r q}+\frac{d \Phi_{r q}}{d t}+\omega_{r} \cdot i_{r d}\end{array}\right.$ 


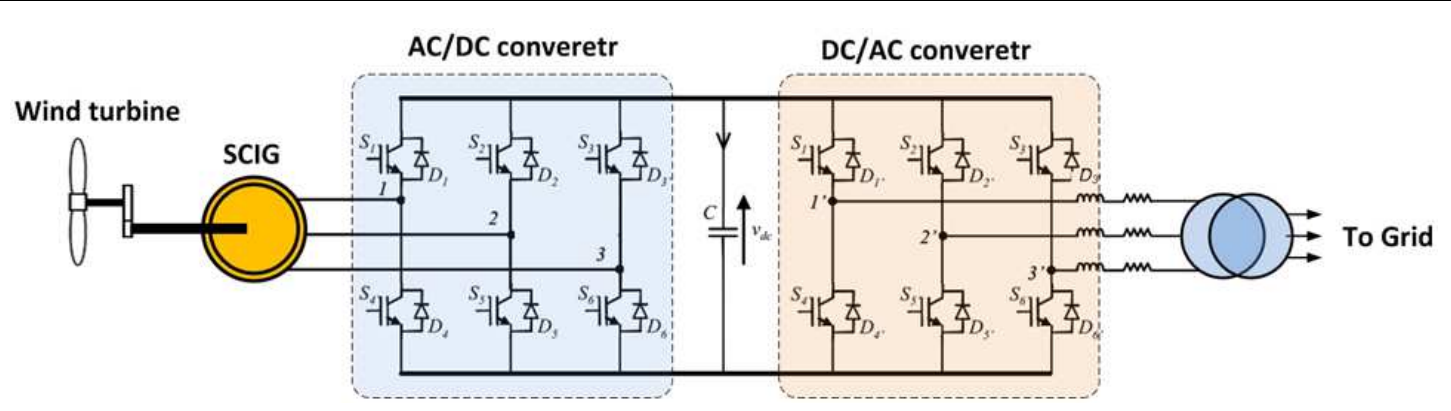

Fig. 1. SCIG-based wind energy conversion system

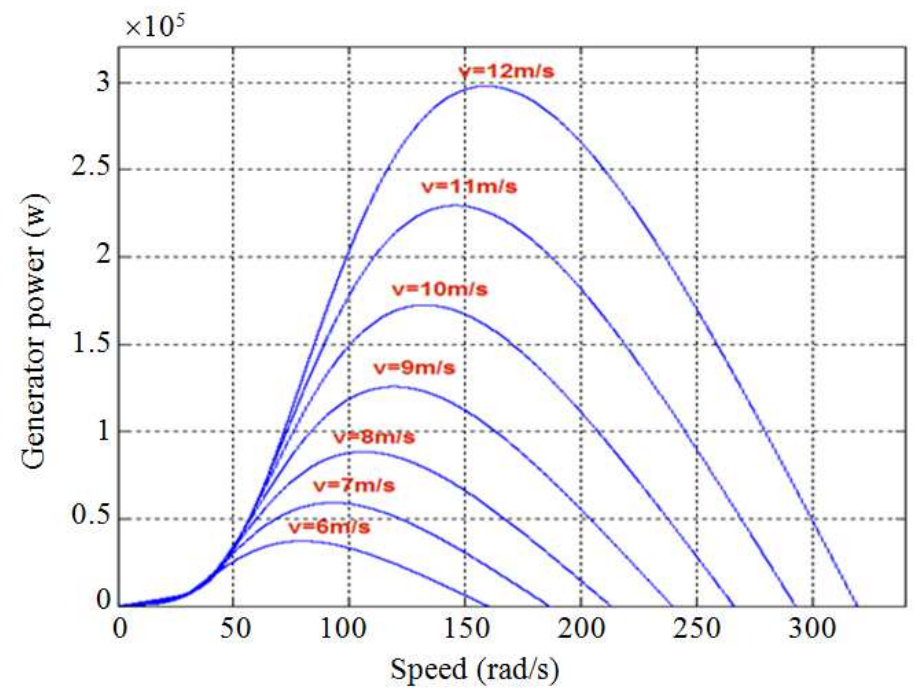

Fig. 2. Generator power as a function of generator speed for different wind speeds

The magnetic flux created by the windings of the stator and the rotor are given by the following relations:

$$
\left\{\begin{array}{l}
\Phi_{s d}=L_{s} I_{s d}+m \cdot L_{m} \cdot I_{r d} \\
\Phi_{s q}=L_{s} I_{s q}+m \cdot L_{m} \cdot I_{r q} \\
\Phi_{r d}=L_{r} I_{r d}+m \cdot L_{m} \cdot I_{s d} \\
\Phi_{r q}=L_{r} I_{r q}+m \cdot L_{m} \cdot I_{s q}
\end{array}\right.
$$

\section{Where:}

$$
\begin{aligned}
& v \quad=\text { The voltage } i \text { the current } \\
& \Phi=\text { The flux } \\
& R \quad=\text { The resistance } \\
& L \quad=\text { Inductance } \\
& M \quad=\text { The mutual inductance } \\
& T_{e m} \quad=\text { The electromagnetic torque } \\
& P \quad=\text { The pole pair number } \\
& L_{m} \text { and } m\left(M=m \cdot L_{m}\right)=\text { Magnetizing inductance and } \\
& \text { turns ratio of the stator current } \\
& \text { and rotor current respectively }
\end{aligned}
$$

The above model (5) to (7) can be presented as differential equations for the stator currents and rotor flux vector components under the following form:

$$
\left\{\begin{array}{c}
\dot{x}_{1}=a_{1}\left(x_{2} \cdot x_{3}-x_{7} \cdot \dot{x}_{4}\right)-a_{2} \cdot x_{1}-a_{3} \cdot x_{8} \\
\dot{x}_{2}=-a_{4} \cdot x_{2}-a_{5} \cdot x_{4}+a_{5} \cdot x_{7}-a_{7} \cdot x_{1} \cdot x_{3}+a_{8} \cdot x_{6} \\
\dot{x}_{3}=a_{9} \cdot x_{4}-a_{10} \cdot x_{3}+a_{5} \cdot x_{7}-a_{11} \cdot x_{1} \cdot x_{7} \\
\dot{x}_{4}-a_{4} \cdot x_{4}+a_{5} \cdot x_{2}+a_{6} \cdot x_{3}+a_{7} \cdot x_{1} \cdot x_{7}+a_{8} \cdot x_{5}
\end{array}\right.
$$

Where:

$$
\begin{aligned}
& a_{1}=\frac{P \cdot M}{J \cdot L_{r}} ; a_{2}=\frac{f}{J} ; a_{3}=\frac{1}{J} ; \\
& a_{4}=\frac{L_{r}^{2} \cdot R_{s}+L_{m}^{2} \cdot R_{r}}{\sigma \cdot L_{s} \cdot L_{r}^{2}} ; a_{5}=1 ; a_{6}=\frac{R_{r} \cdot M}{\sigma \cdot L_{s} \cdot L_{r}{ }^{2}} \\
& a_{7}=\frac{R_{r} \cdot P}{\sigma \cdot L_{s} \cdot L_{r}} ; a_{8}=\frac{1}{\sigma \cdot L_{s}} ; a_{9}=\frac{R_{r} \cdot M}{L_{r}} ; \\
& a_{10}=\frac{R_{r}}{L_{r}} ; a_{11}=P
\end{aligned}
$$

And:

$$
\begin{aligned}
& x_{1}=\omega_{m} ; x_{2}=i_{s q} ; x_{3}=\phi_{r d} ; x_{4}=i_{s d} ; \\
& x_{5}=v_{s d} ; x_{6}=v_{s q} ; x_{7}=\phi_{r q} ; x_{8}=T_{m}
\end{aligned}
$$


Controls the electromagnetic torque and rotor direct flux will be obtained by controlling the dq-axes stator currents of the SCIG.

By choosing the two-phase dq related to rotating rotor field and placing the rotor flux vector on the d-axis, we have $\phi_{r d}=\phi_{r d}=\phi_{r}$ and $\phi_{r q}=0$. In this case, the model (9) becomes Equation 8:

$$
\left\{\begin{array}{c}
\dot{x}_{1}=a_{1} \cdot x_{2} \cdot x_{3}-a_{2} \cdot x_{1}-a_{3} \cdot x_{8} \\
\dot{x}_{2}=-a_{4} \cdot x_{2}-a_{5} \cdot x_{4}-a_{7} \cdot x_{1} \cdot x_{3}+a_{8} \cdot x_{6} \\
\dot{x}_{3}=a_{9} \cdot x_{4}-a_{10} \cdot x_{3} \\
\dot{x}_{4}-a_{4} \cdot x_{4}+a_{5} \cdot x_{2}+a_{6} \cdot x_{3}+a_{8} \cdot x_{5}
\end{array}\right.
$$

\section{Modeling Three-Phase Inverter}

In this section, we focus on the modeling of the $\mathrm{DC} / \mathrm{AC}$ inverter connected to power grid via the $\mathrm{RL}$ filter as illustrated in Fig. 4.

The model of the three-phase grid connected $\mathrm{DC} / \mathrm{AC}$ converter is presented by the following Equation 9 (Mehdi et al., 2013):

$$
\left\{\begin{array}{l}
v_{s 1}=v_{g 1}+R_{g} \cdot i_{g 1}+L_{g} \cdot \frac{d i_{g 1}}{d t} \\
v_{s 2}=v_{g 2}+R_{g} \cdot i_{g 2}+L_{g} \cdot \frac{d i_{g 2}}{d t} \\
v_{s 3}=v_{g 3}+R_{g} i_{g 3}+L_{g} \cdot \frac{d i_{g 3}}{d t}
\end{array}\right.
$$

The dynamic of the DC bus voltage is given by the following Equation 10:

$$
c . \frac{d V_{d c}}{d t}=i_{\text {rec }}-i_{\text {ond }}
$$

\section{Control Strategy}

The architecture of the controller is shown in Fig. 4. It is based on the three-phase model of the electromechanical conversion chain of the wind system (Mehdi et al., 2013).

The control strategy has three objectives:

- Control of AC/DC converter to extract maximum wind power by controlling the electromagnetic torque and d-axis flux of rotor of SCIG

- Control of the DC/AC by controlling the DC bus voltage, active and reactive power Injected to electrical network

\section{MPPT Strategy}

The control objective is to optimize the capture wind energy by tracking the optimal generator speed $\omega_{m}{ }^{*}$.
The optimum speed which corresponds to operation at maximum power is approximated according to the wind speed Equation 11:

$\omega_{m}^{*}=a 0+a 1 . v+a 2 . v^{2}$

With:

$$
a 0=16 ; a 1=9.33 ; a 2=0.2222
$$

\section{Control of the AC/DC Converter}

In order to extracting maximum power from turbine, mechanical speed and rotor flux, two state variables have been proposed for describing the (SCIG) model as follows:

$$
\begin{aligned}
& \dot{x}_{1}=a_{1}\left(x_{2} \cdot x_{3}-x_{7} \cdot x_{4}\right)-a_{2} \cdot x_{1}-a_{3} \cdot x_{8} \\
& \dot{x}_{3}=a_{9} \cdot x_{4}-a_{10} \cdot x_{3}+a_{5} \cdot x_{7}-a_{11} \cdot x_{1} \cdot x_{7}
\end{aligned}
$$

Therfore, the errors are defined using the rotational speed and rotor flux Equation 14 and 15:

$$
\begin{aligned}
& e_{1}=x_{1}-x_{1}^{*} \\
& e_{3}=x_{3}-x_{3}^{*}
\end{aligned}
$$

In Equation 12 and 13, $x_{2}$ and $x_{4}$ behaves as a virtual control input. Such an equation shows that one gets $\dot{e}_{1}=-$ $k_{1} \cdot e_{1}$ and $\dot{e}_{3}=-k_{3} \cdot e_{3} \quad\left(k_{1}>0 ; \quad k_{3}>0\right.$ being a design parameters) provided that Equation 16 and 17:

$x_{2}=\left(a_{2} \cdot x_{1}+a_{3} \cdot x_{8} \cdot-k_{1} e_{1}\right) / a_{1} \cdot x_{3}$

$x_{4}=\left(a_{10} \cdot x_{3}-k_{3} e_{3}\right) / a_{9}$

As $x_{2}$ and $x_{4}$ are just a variables and not (an effective) control inputs, (12)-(13) cannot be enforced for all $t \geq 0$. Nevertheless, Equation 18 and 19 shows that the desired value for the variable $x_{2}$ and $x_{4}$ are respectively:

$$
\begin{aligned}
& x_{2}^{*}=\left(a_{2} \cdot x_{1}+a_{3} \cdot x_{8} \cdot-k_{1} e_{1}\right) / a_{1} \cdot x_{3} \\
& x_{4}^{*}=\left(a_{10} \cdot x_{3}-k_{3} e_{3}\right) / a_{9}
\end{aligned}
$$

Indeed, if the errors Equation 20 and 21:

$$
\begin{aligned}
& e_{2}=x_{2}-x_{2}^{*} \\
& e_{4}=x_{4}-x_{4}^{*}
\end{aligned}
$$




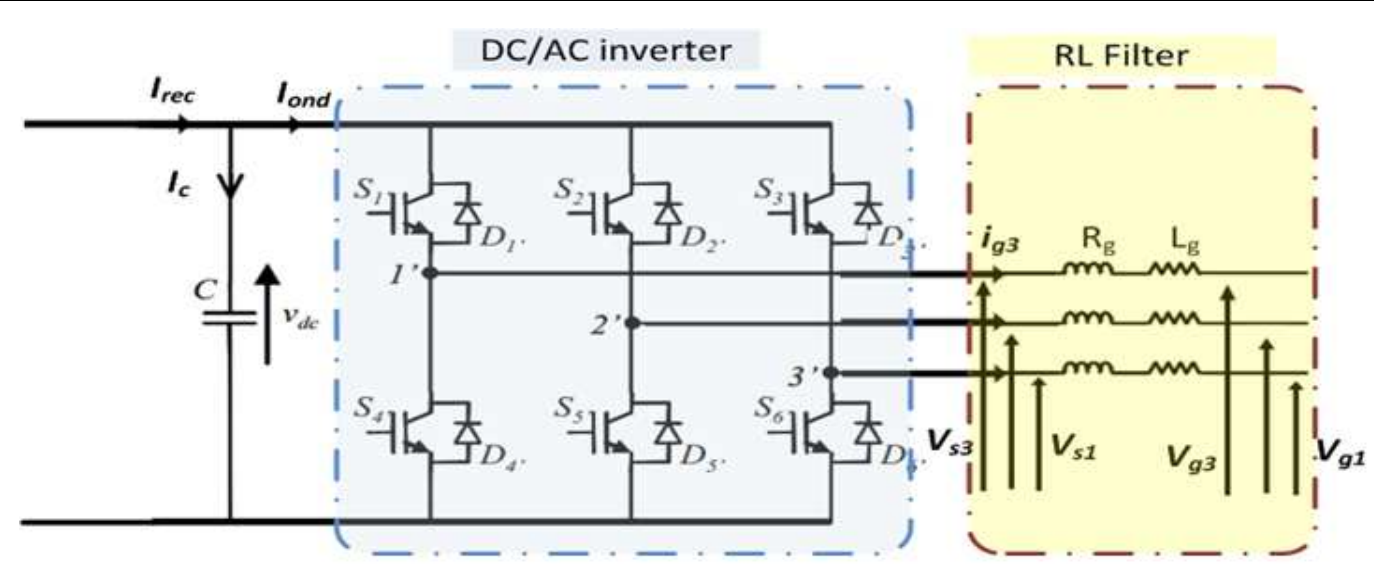

Fig. 3. Three-phase DC/ACinverter

\section{Wind turbine}

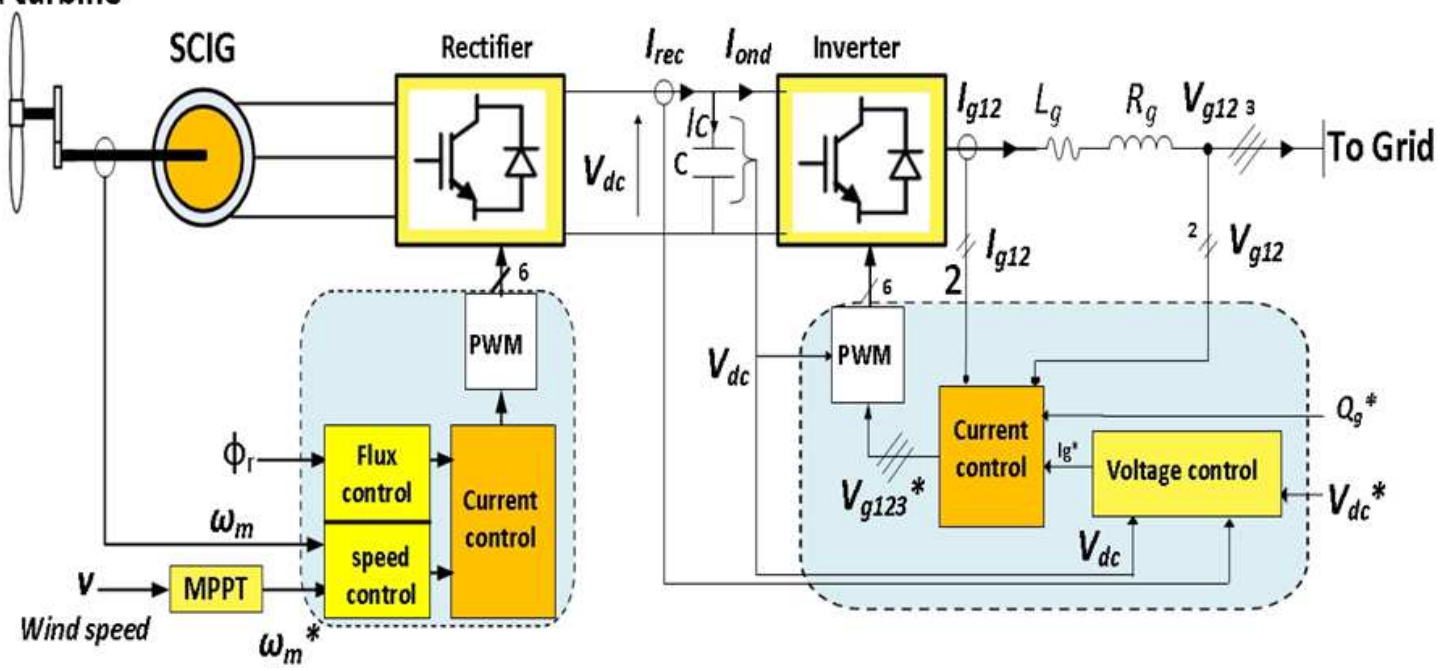

Fig. 4. Control strategy

The desired value $x_{2}^{*}$ and $x_{2}^{*}$ are called a stabilization function.

Deriving $e_{1}$ and $e_{3}$ with respect to time and accounting for (12)-(13)-(18) and (19), implies Equation 22 and 23:

$$
\begin{aligned}
& \dot{e}_{1}=-k_{1} \cdot e_{1}+a_{3} \cdot x_{3} \cdot e_{2} \\
& \dot{e}_{1}=-k_{3} \cdot e_{3}+a_{9} \cdot e_{4}
\end{aligned}
$$

The Lyapunov function is defined as Equation 24:

$V=\frac{e_{1}^{2}}{2}+\frac{e_{2}^{2}}{2}+\frac{e_{3}^{2}}{2}+\frac{e_{4}^{2}}{2}$

The time derivative of Lyapunov function $V$ is given by Equation 25:
$\dot{V}=e_{1} \cdot \dot{e}_{1}+e_{2} \cdot \dot{e}_{2}+e_{3} \cdot \dot{e}_{2}+e_{4} \cdot \dot{e}_{4}$

The time-derivative of the latter, along the $\left(e_{1}, e_{2}, e_{3}, e_{4}\right)$ trajectory is Equation 26 :

$$
\dot{V}=-k_{1} \cdot e_{1}^{2}-k_{2} \cdot e_{2}^{2}-k_{3} \cdot e_{3}^{2}-k_{4} \cdot e_{4}^{2} \leq 0
$$

Then, the control $\left(x_{5}^{*}=v_{s d}^{*}, x_{6}^{*}=x_{s q}^{*}\right)$ laws are derived Equation 27 and 28:

$$
\begin{aligned}
& x_{5}^{*}=\left(-a_{9} \cdot e_{3}+a_{4} \cdot x_{4}-k_{4} e_{4}-a_{6} \cdot x_{3}-\dot{a}_{5} \cdot x_{2}+x_{4}^{*}\right) / a_{8} \\
& x_{6}^{*}=\left(-a_{3} \cdot e_{1} \cdot x_{3}+a_{4} \cdot x_{2}+a_{5} \cdot x_{4}-k_{2} e_{2}+a_{7} \cdot x_{1} \cdot x_{3}+\dot{x}_{2}^{*}\right) / a_{8}
\end{aligned}
$$

\section{DC/AC Control Strategy}

The three-phase grid connected inverteris controled to: 
- $\quad$ Regulating the dc bus voltage

- Provide a power factor close to unity (network current in phase with the network voltage)

Applying $d q$ transformation and developing the equations system (9), it is possible to find the differential Equation 29:

$$
\left\{\begin{array}{l}
v_{d}=R_{g} i_{d}+L_{g} \frac{d i_{d}}{d t}+L_{g} \cdot \omega \cdot i_{q}+v_{g d} \\
v_{q}=R_{g} i_{q}+L_{g} \frac{d i_{q}}{d t}+L_{g} \cdot \omega \cdot i_{d}+v_{g q}
\end{array}\right.
$$

where, $\left(v_{g \mathrm{~d}}, v_{g \mathrm{q}}\right)$ are the direct and quadrature components of the grid voltage respectively. $\left(i_{\mathrm{d}}, i_{\mathrm{q}}\right)$ are the direct and quadrature components of the grid current.

The term $\omega \cdot L_{\mathrm{g}} \cdot i_{\mathrm{q}}+v_{\mathrm{gd}}$ and $-\omega \cdot L_{\mathrm{g}} \cdot \mathrm{i}_{\mathrm{d}}+v_{\mathrm{gq}}$ are compensated by a feed-forward action. By applying the Laplace transform to the compensated system, the transfer function of the inverter is given as Equation 30:

$$
G_{i}(p)=\frac{v_{d}}{\mathrm{i}_{d}}=\frac{v_{q}}{i_{q}}=\frac{1}{\mathrm{~L}_{g} \cdot \mathrm{p}+\mathrm{R}_{g}}
$$

where, $v_{\mathrm{d}}$ and $v_{\mathrm{q}}$ are the inputs inverter voltages and the $i_{\mathrm{d}}$ and $i_{\mathrm{q}}$ are the outputs currents respectively.

The DC bus dynamics is given as Equation 31:

$$
c . \dot{\bar{V}}_{d c}=i_{\text {rec }}-i_{\text {ond }}
$$

The application of the Laplace transform to (24) result in Equation 32:

$$
c \cdot p \cdot \bar{V}_{d c}=i_{\text {rec }}-i_{\text {ond }}
$$

The term $i_{\text {rec }}$ is a disturbance in the control. It is assumed in this study that the DC bus loop is sufficiently fast, as to eliminate the perturbation term. For this reason, the DC bus function will be Equation 33:

$$
G_{u}(p)=\frac{V_{d c}}{\mathrm{i}_{\text {ond }}}=-\frac{1}{\mathrm{c} \cdot \mathrm{p}}
$$

The control loops of the inverter are shown in Fig. 5. Externally, there is the reactive power loop that controls the power factor and the loop to regulate the DC bus voltage. The current control loops use proportionalintegral controllers. The controller gains are adjusted by the poles allocation method (Dinghui et al., 2009).

\section{Simulation Results}

The model of the wind turbine system based (SCIG) is built using MATLAB $\backslash S I M U L I N K$. The parameters of the turbine and (SCIG) are given in the Table 1.

Table 1. Parameters of the turbine and (SCIG)

\begin{tabular}{ll}
\hline System & Parameter \\
\hline Turbine & $\mathrm{Jt}=50 \mathrm{~kg} \cdot \mathrm{m}^{2}$, \\
& $\mathrm{Vt}_{\mathrm{n}}=12 \mathrm{~m} / \mathrm{s}, \mathrm{R}=14 \mathrm{~m}$ \\
Multiplier & $\mathrm{Mu}=46$ \\
SCIG & $\mathrm{U}_{\mathrm{s}}=\mathrm{U}_{\mathrm{r}}=575 \mathrm{~V}, \mathrm{P}_{\mathrm{n}}=300 \mathrm{Kw}$, \\
& $\omega_{\mathrm{n}}=160 \mathrm{rad} / \mathrm{s}, \mathrm{f}=50 \mathrm{~Hz}$, \\
& $\mathrm{R}_{\mathrm{r}}=46 \mathrm{~m} \Omega, \mathrm{R}_{\mathrm{s}}=63 \mathrm{~m} \Omega$, \\
& $\mathrm{M}=11.6 \mathrm{mH}, \mathrm{L}_{\mathrm{s}}=11.8 \mathrm{mH}$, \\
& $\mathrm{L}_{\mathrm{r}}=11.8 \mathrm{mH}, \mathrm{P}=2$ \\
DC BUS & $\mathrm{C}=20 \mathrm{mF}, \mathrm{V}_{\mathrm{dc}}=1000 \mathrm{~V}$ \\
RL Filter & $\mathrm{R}_{\mathrm{g}}=0.1 \Omega, \mathrm{L}_{\mathrm{g}}=0.6 \mathrm{mH}$ \\
GRID & $\mathrm{U}_{\mathrm{g}}=575 \mathrm{~V}, \mathrm{f}=50 \mathrm{~Hz}$ \\
\hline
\end{tabular}

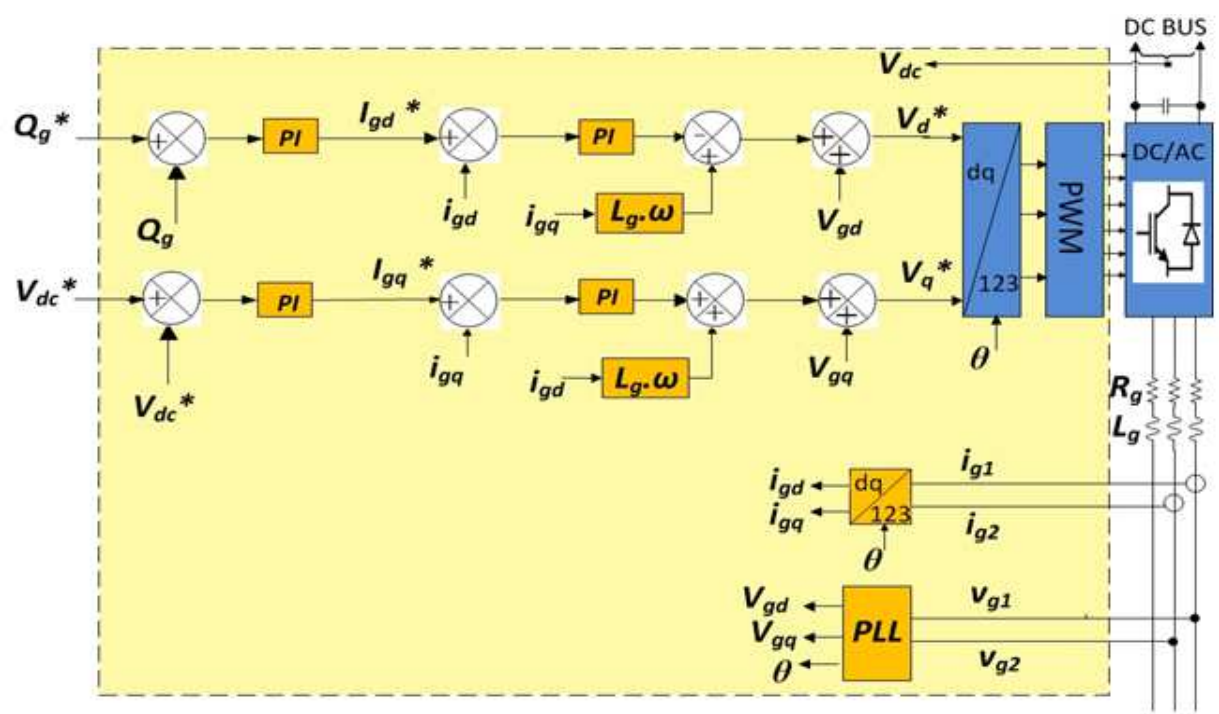

GRID

Fig. 5. Control strategy of the grid connected DC/AC converter 


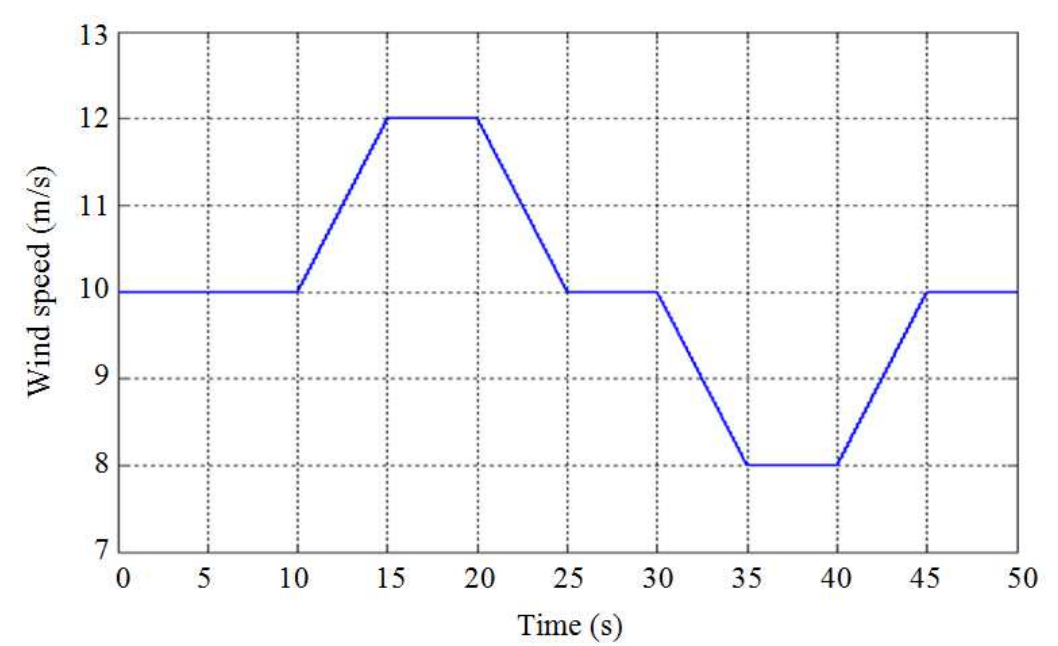

(a)

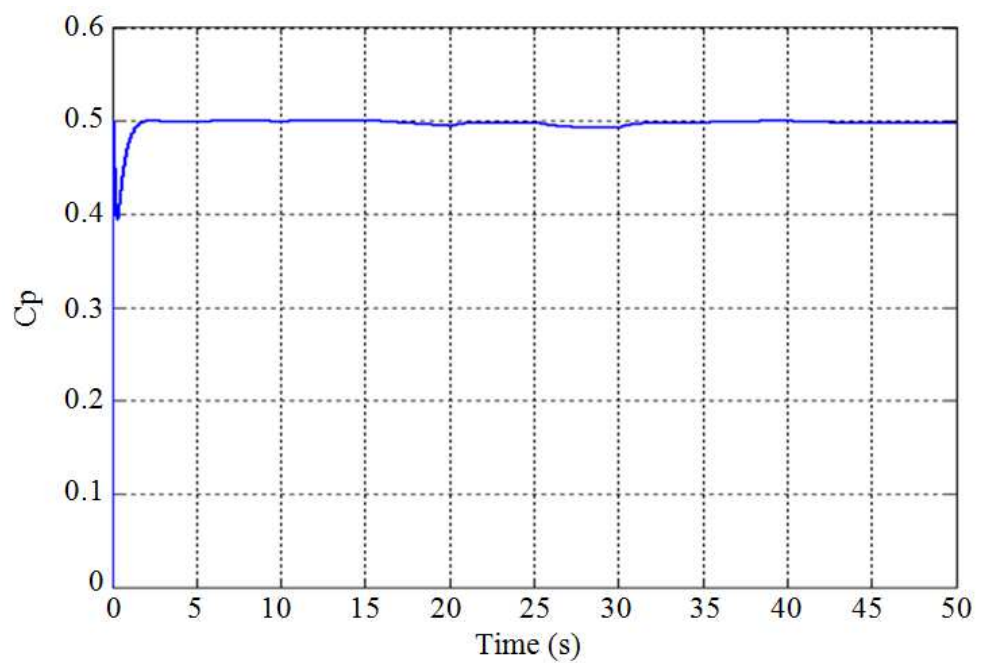

(b)

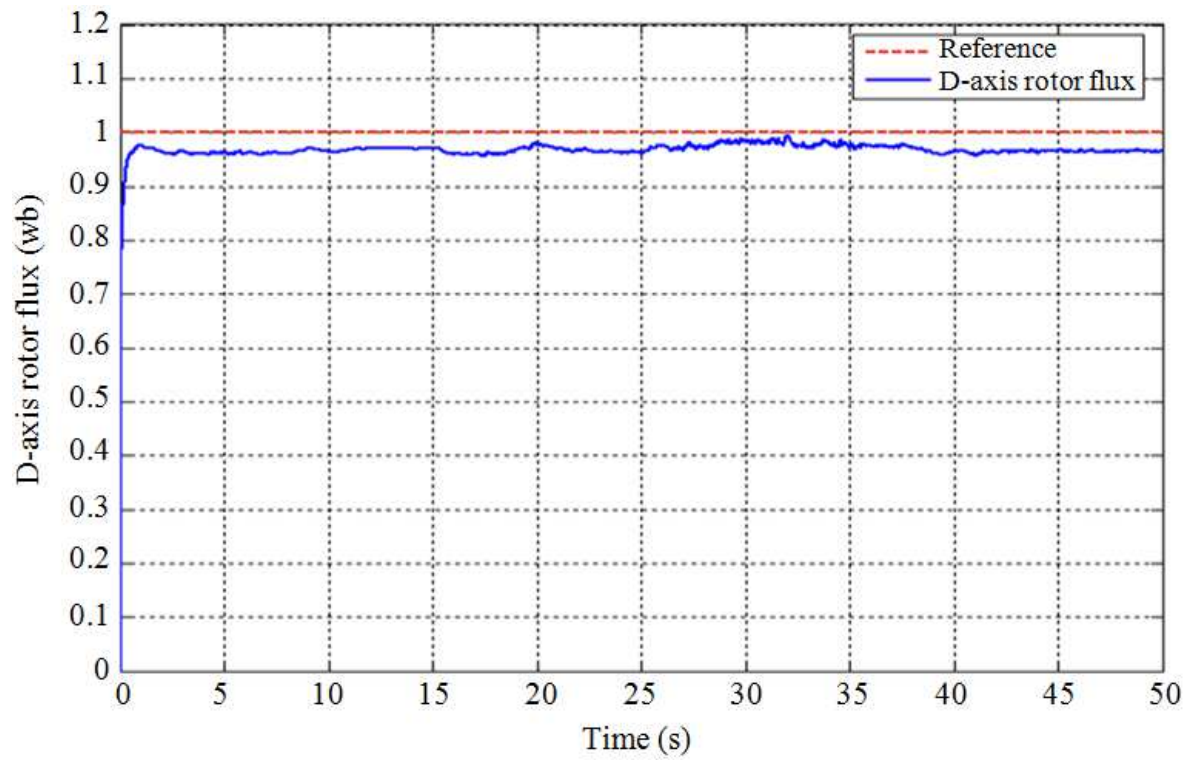

(c) 


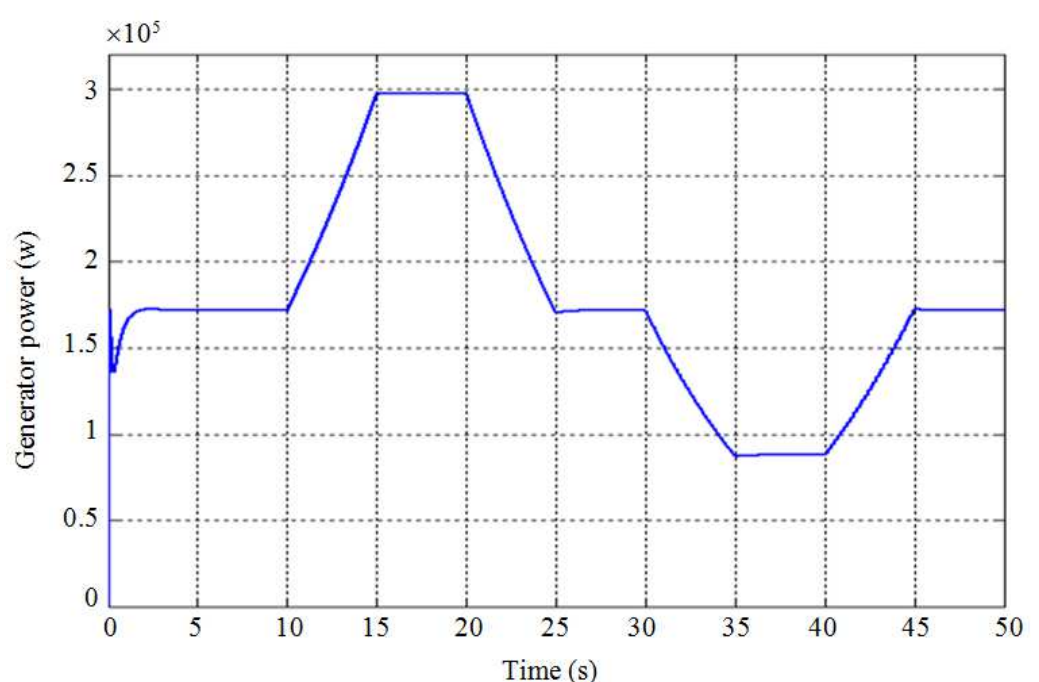

(d)

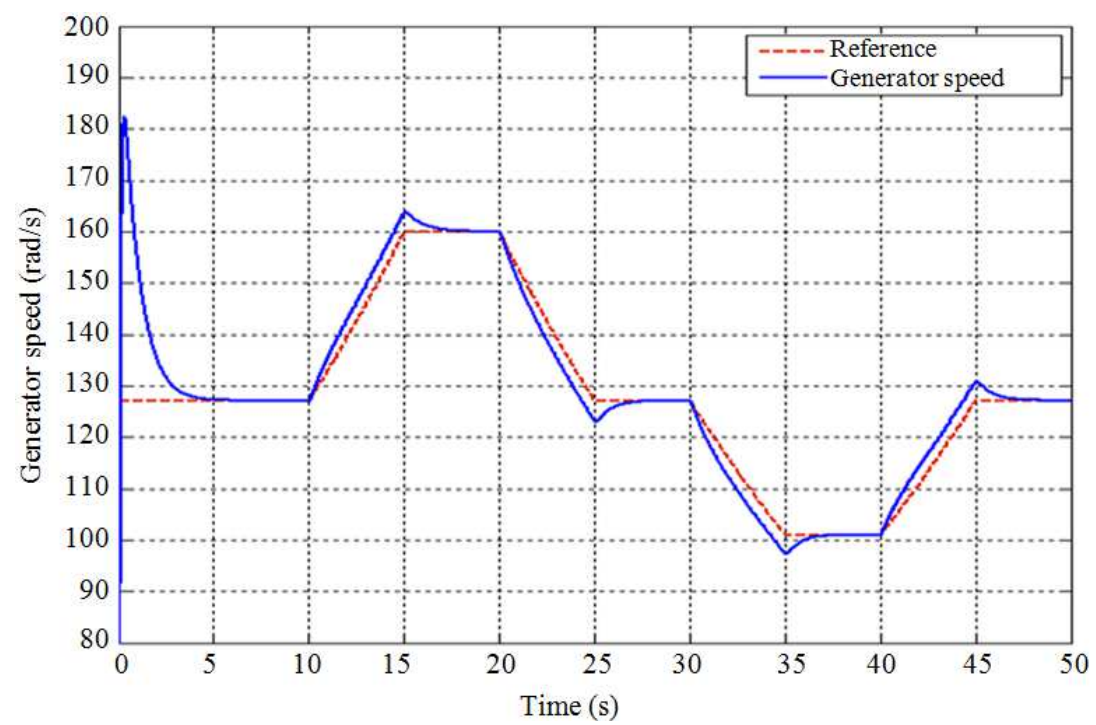

(e)

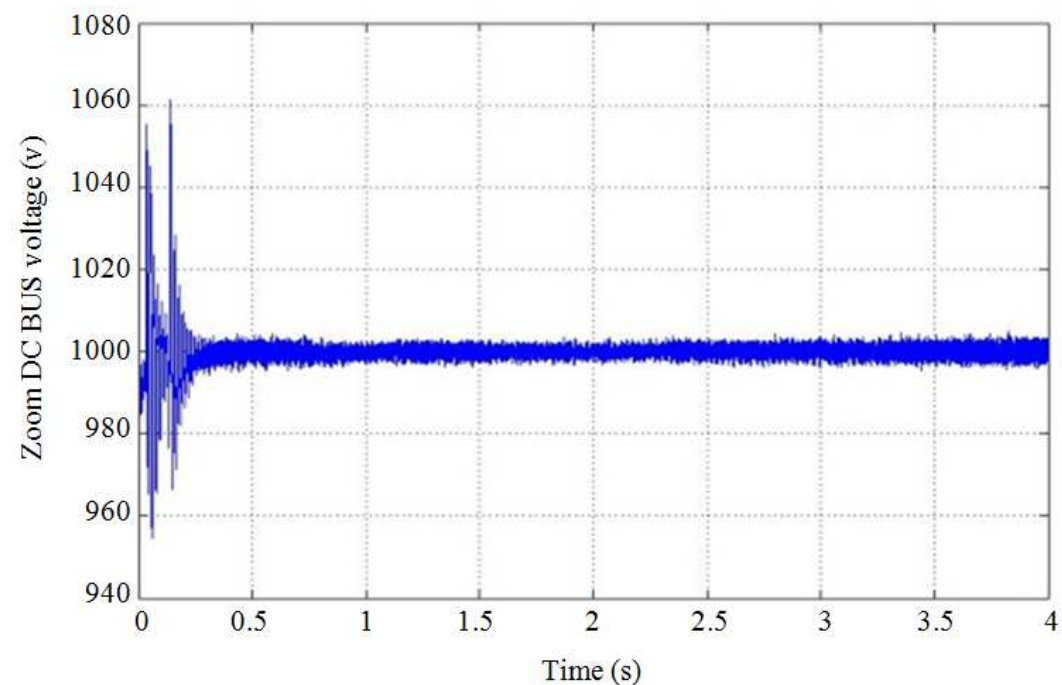

(f) 


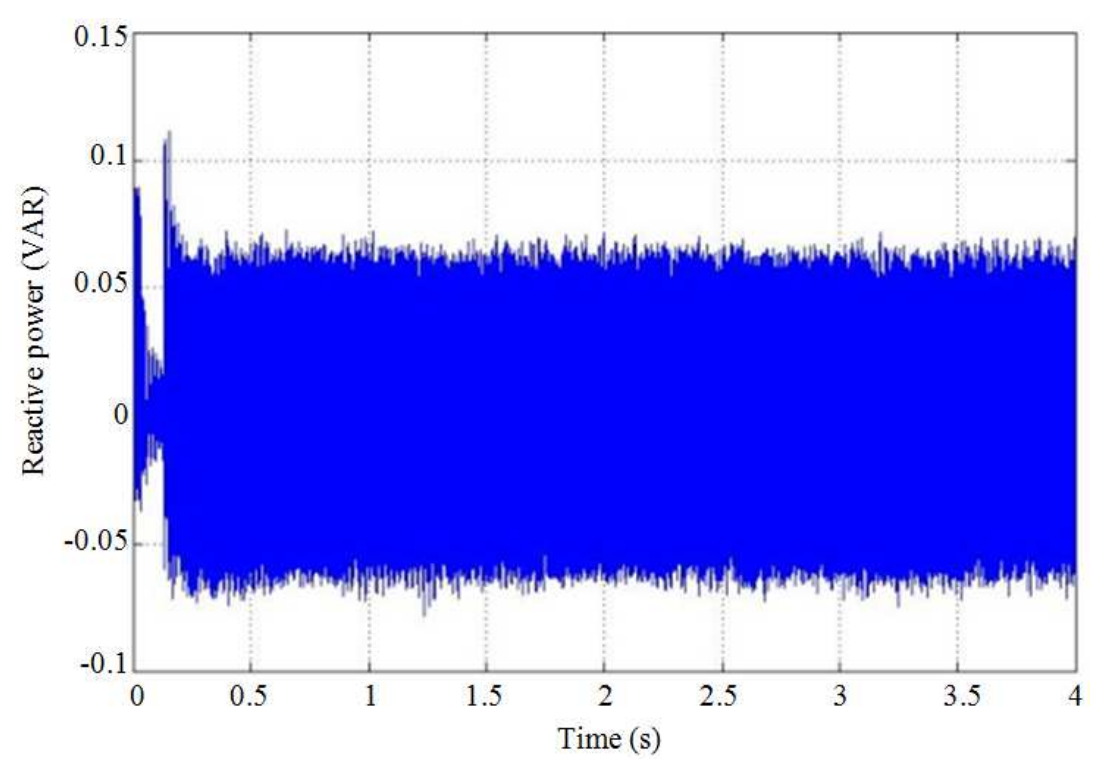

(g)

Fig. 6. Simulations results (a) Wind velocity (b) Power coefficient Cp (c) d-axis rotor flux and reference (d)Generator Power (e) Generator speed and reference (f) DC bus Voltage (g) Reactive power

Figure 6 shows the response system for a wind change velocity. Figure $6 a$ shows the wind velocity profile imposed. Figure $6 \mathrm{~b}$ shows the power coefficient $\mathrm{Cp}$. According to this figure, the power coefficient $\mathrm{Cp}$ is adjusted to its optimum value $(\mathrm{Cp}=0.5)$.

Figure $6 \mathrm{c}$ shows the $\mathrm{d}$-axis rotor flux. We note that the $\mathrm{d}$-axis rotor flux is regulated to its reference value $\left(\phi_{\mathrm{r}}=1 \mathrm{wb}\right)$.

Figure 6d shows the mechanical power extracted from the wind power generator. According to Fig. 3, the extracted power is maximum.

Figure 6e shows the speed of the SCIG machine. We note that the speed is regulated at the reference estimated by the MPPT.

Figure 6f shows the DC bus voltage. The reference of the DC bus voltage denoted $\mathrm{V}_{\mathrm{dc}} *$ is set at $1000 \mathrm{~V}$. According to this figure, the DC bus voltage is regulated to its reference.

Figure $6 \mathrm{~g}$ shows the reactive power injected to the grid. The reference value of reactive power $\mathrm{Qg} *$ is set to $0 \mathrm{VAr}$, which guarantees a power factor close to unity. The reactive power of stator Qs is regulated to reference value.

\section{Conclusion}

This study has addressed the modeling and control of a wind system with variable speed of the wind based on a SCIG. We are interested in modeling of various components of wind system. In fact, the aerodynamic and mechanical models of the turbine have been developed. In order to establish different controllers of two converters, we have developed models of SCIG and liaison of the SCIG to the network via the inverter and RL filter.

To validate the modeling and control of the global wind system, we have performed a simulation for an operating point at variable wind speed.

According to the simulation results, the control strategy allowed regulation of the generator speed to the optimal value estimated by the MPPT algorithm. On the other hand a good decoupling between the adjustment of $\mathrm{d}$-axis rotor flux and the generator speed. Finally, operating at a near-unity power factor at the injection of extracted of wind power into the grid system.

\section{Funding Information}

There is no funding for this work. this work is developed in a personal capacity

\section{Ethics}

This scientific research work is developped in the direction of improving the pruduction energitic for a global population increasingly growing and also to respond to the global economic demand.

\section{References}

Dinghui, W., L. Yuanlong and J. Zhicheng, 2009. Modeling and MPPT control of squirrel-cage induction generator wind power generation system via VisSim. Proceedings of the Chinese Control and Decision Conference, Jun. 17-19, IEEE Xplore Press, Guilin, pp: 48-53. DOI: 10.1109/CCDC.2009.5195147 
Kedjar, B. and K. Al-Haddad, 2012. Optimal control of a grid connected variable speed wind energy conversion system based on squirrel cage induction generator. Proceedings of the 38th Annual Conference on IEEE Industrial Electronics Society,Oct. 25-28, IEEE Xplore Press, Montreal, QC., pp: 3560-3565. DOI: 10.1109/IECON.2012.6389327

Manaullah, M., A.K. Sharma, H. Ahuja, G. Bhuvaneswari and R. Balasubramanian, 2012. Control and dynamic analysis of grid connected variable speed SCIG based wind energy conversion system. Proceedings of the 4th International Conference on Computational Intelligence and Communication Networks, Nov. 3-5, IEEE Xplore Press, Mathura, pp: 588-593. DOI: 10.1109/CICN.2012.74

Mehdi, A., A. Boulahia, H. Medouce and H. Benalla, 2013. Induction generator using AC/DC/AC PWM converters and its application to the wind-energy systems. Proceedings of the IEEE EUROCON, Jul. 1-4, IEEE Xplore Press, Zagreb, pp: 1038-1043. DOI: 10.1109/EUROCON.2013.6625109
Mesemanolis, A. and C. Mademlis, 2013. Self-tuning maximum power point tracking control for wind generation systems. Proceedings of the International Conference on Clean Electrical Power, Jun. 11-13, IEEE Xplore Press, Alghero, pp: 407-413. DOI: 10.1109/ICCEP.2013.6587022

Suebkinorn, W., and B. Neammanee, 2011. An implementation of field oriented controlled SCIG for variable speed wind turbine. Proceedings of the 6th IEEE Conference on Industrial Electronics and Applications, Jun. 21-23, IEEE Xplore Press, Beijing, pp: 39-44.

DOI: 10.1109/ICIEA.2011.5975547

Trapp, J.G., F.A. Farret, F.T. Fernandes and L.C. Correa, 2012. Variable speed wind turbine using the squirrel cage induction generator with reduced converter power rating for stand-alone energy systems. Proceedings of the 10th IEEE/IAS International Conference on Industry Applications, Nov. 5-7, IEEE Xplore Press, Fortaleza, pp: 1-8. DOI: 10.1109/INDUSCON.2012.6453324 